\title{
Predicting preoperative pulmonary function in patients with thoracic adolescent idiopathic scoliosis from spinal and thoracic radiographic parameters
}

\author{
James Farrell ${ }^{1}\left[\right.$ ] Enrique Garrido ${ }^{2}$
}

Received: 24 March 2020 / Revised: 10 June 2020 / Accepted: 23 July 2020 / Published online: 30 July 2020

(c) The Author(s) 2020

\begin{abstract}
Purpose The objective was to analyse the effect of thoracic morphology on pulmonary function in adolescent idiopathic scoliosis (AIS) to predict preoperative lung function.

Methods A total of 170 consecutive preoperative patients (average age 15.1 years) with Lenke 1 and 2 AIS underwent pulmonary function testing. Thirteen deformity parameters, including rib hump size, rib asymmetry, spinal intrusion and thoracic/ lung dimensions in the sagittal and coronal plane, were measured on whole-spine radiographs. Lung function parameters were expressed as z-scores. Correlation and regression analysis of these parameters with lung function were performed.

Results Mean thoracic Cobb (MT) was 69.1 $1^{\circ}$, and mean T5-T12 thoracic kyphosis (TK) was $21.8^{\circ}$. MT correlated significantly with $\mathrm{FEV}_{1}$ and FVC $\left(r_{\mathrm{s}}=-0.40\right.$ and -0.38$)$. TK correlated weakly with $\mathrm{FEV}_{1}$ and $\mathrm{FEV}_{1} / \mathrm{FVC}\left(r_{\mathrm{s}}=0.23\right.$ and 0.25$)$. $\mathrm{FEV}_{1}$ and $\mathrm{FVC}$ were best predicted by the inverse apical vertebra body-rib ratio $\left(\mathrm{AVBRr}^{-1}, r_{s}=0.46\right.$ and 0.42$)$, rib hump depth index (RHDi, $r_{\mathrm{s}}=-0.52$ and -0.50$)$ and spinal intrusion ratio ( $\mathrm{SIr}, r_{\mathrm{s}}=-0.50$ and -0.45 ). The kyphosis-lordosis index (KLi) correlated with $\mathrm{FEV}_{1} / \mathrm{FVC}\left(r_{\mathrm{s}}=0.29\right)$. Multivariate regression analysis of coronal and sagittal Cobb angles produced a model which explained $35 \%$ and $30 \%$ of the variance in $\mathrm{FEV}_{1}$ and $\mathrm{FVC}$, whilst a regression model consisting of $\mathrm{AVBRr}^{-1}$ and SIr was able to predict $54 \%$ and $48 \%$.

Conclusion $\mathrm{AVBRr}^{-1}$, RHDi and SIr measured on posterior-anterior and lateral radiographs provide better estimations of lung function in preoperative AIS patients than Cobb measurements. KLi was an indicator of airway obstruction as measured by $\mathrm{FEV}_{1} / \mathrm{FVC}$.
\end{abstract}

Keywords Pulmonary function tests · Scoliosis · Thoracic deformity $\cdot$ Rib hump $\cdot$ Spinal intrusion

Electronic supplementary material The online version of this article (https://doi.org/10.1007/s00586-020-06552-y) contains supplementary material, which is available to authorized users.

James Farrell

j.farrell@ed.ac.uk

Enrique Garrido

enrique.garrido@nhslothian.scot.nhs.uk

1 School of Engineering, The University of Edinburgh, Edinburgh, UK

2 Scottish National Spine Deformity Service, Royal Hospital for Sick Children, Edinburgh, UK

\section{Introduction}

Management of thoracic adolescent idiopathic scoliosis (AIS) is still generally based on the Cobb angle method. However, the association between spinal deformity and respiratory function is weak [1-5]. Better radiographic predictors of pulmonary function are required to evaluate outcomes of treatment, anticipate respiratory deterioration and estimate respiratory volumes in patients with thoracic scoliosis who cannot comply with spirometry standards.

The combined spine and rib cage deformity in AIS is best conceptualised as a thoracic deformity [6]. Although numerous radiographic and computed tomographic (CT) parameters have been proposed to describe the thoracic configuration [6-8], research into the role of the thoracic deformity in impairing lung function has been limited to a few studies [9-13]. This study aims to analyse the effect of 
thoracic morphology on pulmonary function and produce better predictive models of lung function in thoracic AIS patients.

\section{Materials and methods}

\section{Subject characteristics}

After institutional review board approval, a retrospective review of the surgeon's imaging database between 2015 and 2019 (Kodak Carestream PACS) at a national spinal deformity centre was conducted to identify AIS patients with right-sided Lenke type 1 or 2 curves with an apex between the 7 th and 10th thoracic vertebrae. Consecutive patients who underwent radiographic examination and pulmonary function tests (PFTs) during preoperative assessment were included. Patients with evidence or a history of primary obstructive lung disease and patients with a positive result to bronchodilator reversibility testing were excluded.

\section{Radiographic parameters}

Radiographic parameters on preoperative whole-spine standing posteroanterior (PA) and lateral radiographs were measured by the first author. Using the Cobb method, the main thoracic curve (MT), proximal thoracic curve (PT) and T5-T12 thoracic kyphosis (TK) were measured. In addition, 13 radiographic deformity and lung parameters were measured to capture frontal and sagittal dimensions of the thorax, rib asymmetry, rib hump size and spinal intrusion. The definition of these parameters can be found in Table 1, and landmarks are shown in Fig. 1.

On PA radiographs, the rib vertebra angle difference (RVAD) [14], inverse of the apical vertebral body-rib ratio $\left(\mathrm{AVBRr}^{-1}\right)$ [15], space available for lung (SAFL) [16], thoracic height-width ratio (THWr), lung height-width ratio (LHWr), the right and left diaphragm vertebral levels $\left(D L_{R}\right.$ and $\mathrm{DVL}_{\mathrm{L}}$, respectively) and right-left diaphragm vertebral level difference $\left(\mathrm{DVL}_{\text {diff }}\right)$ were measured. On lateral radiographs, the kyphosis-lordosis index (KLi) [17], rib hump index (RHi), rib hump depth index (RHDi), spinal intrusion ratio (SIr) and the sternovertebral depth ratio (SVDr) were measured.

\section{Lung function}

PFTs were conducted via forced manoeuvres in accordance with the joint American Thoracic Society and European Respiratory Society standards [18]. Forced expiration in $1 \mathrm{~s}$ $\left(\mathrm{FEV}_{1}\right)$ and forced vital capacity (FVC) were measured (Jaeger Master-Screen PFT pro) along with arm span. In calculating lung function reference values, arm span was used to estimate standing height to correct for scoliotic height loss [19]. Estimated standing height, sex, race and age at time of testing were used to determine spirometry reference values based on reference equations by the Global Lung Function Initiative [20]; $\mathrm{FEV}_{1}, \mathrm{FVC}$ and the $\mathrm{FEV}_{1} / \mathrm{FVC}$ ratio are expressed as $z$-scores (per cent-predicted results can be found in the electronic supplementary material). The proportion of patients with lung function below the 'lower limit of normal' (LLN), defined as the 5 th percentile of the reference population ( $z$-score of - 1.645), are also reported. Consistent with prior studies, $\mathrm{FEV}_{1}$ and $\mathrm{FVC}$ are also reported in terms of 'mild' (between $60 \%$ and $80 \%$ of predicted), 'moderate' (between $50 \%$ and $60 \%$ of predicted) and 'severe' impairment (below $50 \%$ of predicted) [2].

\section{Statistical methods and predictive model}

Based on the Shapiro-Wilk test, the data contained variables which were not normally distributed $(p<0.001)$. As such, Spearman rank correlation coefficients $\left(r_{\mathrm{s}}\right)$ were used to determine the relationship between PFT variables, Cobb angles, lung parameters and deformity parameters. The $p$ values from Spearman correlations were corrected for multiple comparisons ( $q$ values) using the Benjamini and Yekutieli method [21] with a $q$ value threshold of 0.05 corresponding to a false discovery rate of 5\%. Cobb angles and deformity parameters were used as predictors in LASSO (least absolute shrinkage and selection operator) regression to predict lung function $z$-scores. LASSO is a regularised regression method that includes a tuning parameter, $\lambda$, which shrinks the regression coefficient of poor predictors towards zero. The optimum tuning parameter, $\lambda_{\text {min }}$, was determined from a grid search which yielded the model with the lowest ten times tenfold cross-validated root mean squared error (RMSE). Based on the one standard error rule, the largest $\lambda$ within one standard error from the optimum, $\lambda_{1 \mathrm{SE}}$, was selected for the best predictive model. Bootstrapping over 1000 realisations was performed to estimate the $p$ values for individual predictors. Ordinary least squares (OLS) regression was performed using promising predictors selected from LASSO. The standardised regression coefficients for individual predictors $(\beta)$, the coefficient of determination $\left(R^{2}\right)$ and the RMSE are reported for each regression model. All statistical analysis was implemented using the statistical software R v3.5.1 (http://www.R-project.org) with 'MASS' and 'caret' packages.

\section{Results}

\section{Cohort description}

A summary of subject characteristics is shown in Table 2. A total of 170 patients ( 121 female and 49 male) with a mean 
Table 1 Radiographic thoracic deformity and lung parameters and their definitions. Location of landmarks can be found in Fig. 1

Parameter Definition Formula ${ }^{1}$

Rib vertebra angle difference (RVAD) [14]

Inverse apical vertebral body-rib ratio $\left(\mathrm{AVBRr}^{-1}\right)[15]$

Thoracic height-width ratio (THWr)

Space available for lung (SAFL)

Lung height-width ratio (LHWr)

Right, left diaphragmatic vertebral level $\left(\mathrm{DVL}_{\mathrm{R}}, \mathrm{DVL}_{\mathrm{L}}\right) \mathrm{P}$

Diaphragmatic vertebral level difference $\left(D L_{\text {diff }}\right)$

Kyphosis-lordosis index (KLi) [17]

Spinal intrusion ratio (SIr)

Rib hump depth index (RHDi)

Rib hump index (RHi)

Sternovertebral depth ratio (SVDr)

\footnotetext{
${ }^{1}$ Harpoon arrows denote the distance between landmarks
}

Points $F$ and $E$ (Fig. 1a) were used to define the central position of the right and left hemidiaphragms, respectively. The diaphragmatic level was referenced to the vertebral centroid immediately above $(v)$. In the example shown, $v=10$ (referenced to T10) and $\mathrm{DVL}_{\mathrm{L}}$ has a value of $10+a / b$ where $a$ is the vertical distance from the superior vertebral centroid to the level of the hemidiaphragm, whilst $b$ is the vertical distance between vertebral body centroids.

A line is drawn perpendicular to the inferior apical vertebral endplate. See reference Lines are drawn from the mid-neck to the mid head of the corresponding pair of ribs. RVAD is the difference between the concave and convex angle formed between the rib lines and the line perpendicular to the vertebral endplate. between the lateral border of the vertebrae column and the chest on the convex and concave side is measured. $\mathrm{AVBRr}^{-1}$ is the ratio of the convex side to the concave side.

The height of the thorax is defined as the vertical height between $\mathrm{T} 1$ and T12 vertebral body centroids. THWr is defined by the ratio between the thoracic height and the thoracic width measured at the apex.

The height of the hemithorax is defined as the distance from the middle of the most cephalad rib down to the centre of the hemidiaphragm. SAFL is defined by the ratio between the concave and convex heights, expressed as a percentage.

The chest width is measured horizontally between the interior surfaces of the chest walls at the level of the apical vertebrae. Using the average of height measurements from SAFL, LHWr is the average height

$D V L_{\text {diff }}$ was defined as $D V L_{L}$ less $D V L_{R}$ with positive values indicating a higher right hemidiaphragm.

A line is drawn between T1 and T12 vertebral body centroids. At the mid-point, a horizontal line is drawn until the anterior contour of the vertebral column is met. $\mathrm{KLi}$ is the ratio between the horizontal distance and the T1-T12 line expressed as a percentage. If the anterior contour of the vertebral contour is anterior to the T1-T12 mid-point, the index is negative.

A line is drawn between T1 and T12 vertebral body centroids. At the mid-point, a horizontal line is drawn. SIr is the ratio between the distance from the anterior vertebral column contour to the interior contour of the convex ribs and the distance from the internal sternal surface to the anterior contour of the vertebral column.

A line is drawn between T1 and T12 vertebral body centroids. At the mid-point, a horizontal line is drawn. The horizontal distance from the anterior contour of the vertebral column to the interior contour of the convex rib hump is measured. RHDi is the ratio between the horizontal distance and the length of the T1-T12 centroid line.

A horizontal line is drawn at the level where convex rib hump is most prominent. The distance between the anterior contour of the vertebral column and the internal contour of the concave and convex ribs are measured. The RHi is defined as the ratio between the concave and convex distances subtracted from unity.

A line is drawn between T1 and T12 vertebral body centroids. At the mid-point, a horizontal line is drawn. SVDr is the ratio between the sternovertebral distance and the length of the T1-T12 centroid line. 
Fig. 1 Landmarks used to define radiographic deformity parameters. Definitions of deformity parameters can be found in Table 1. a PA radiograph: Line $L_{1}$ is a horizontal line drawn at the apical vertebra. Along line $L_{1}$, points $B$ and $C$ are the concave and convex lateral borders of the spinal column, whilst points $A$ and $D$ are the concave and convex interior borders of the chest, respectively. Points $E$ and $F$ are the centres of the concave and convex hemidiaphragms, respectively. Points $\mathrm{G}$ and $\mathrm{H}$ are the centres of the cephalad portion of the first rib on the concave and convex side, respectively. Points $I$ and $J$ are the centroids of first (T1) and twelfth (T12) thoracic vertebral bodies, respectively. $\mathrm{DVL}_{\mathrm{R}}$ and $\mathrm{DVL}_{\mathrm{L}}$ were measured on a scale based on vertebral body centroids; in the example shown that $\mathrm{DVL}_{\mathrm{L}}$ would have a value of $10+\mathrm{a} / \mathrm{b}$. b Lateral radiograph: Points $T$ and $U$ are the centroids of T1 and T12, respectively. Line $L_{2}$ is a line drawn between points $T$ and $U$, whilst point $M$ is the mid-point. Line $L_{3}$ is a horizontal line drawn at point $M$. Along line $L_{3}$, point $K$ is the intersection of the interior contour of the sternum; point $N$, the intersection of the anterior contour of the vertebral column; and point $P$, the intersection of the interior contour of the convex rib hump. Line $L_{4}$ is a horizontal line drawn at the apex of the convex rib prominence. Along line $L_{4}$, point $Q$ marks the intersection of the anterior contour of the vertebral column; point $R$, the intersection of the interior concave rib contour; and point $S$, the intersection of the interior convex rib contour, respectively

age of 15.1 years (standard deviation $[\mathrm{SD}]=3.5$ years, range 10.0-39.8 years; 12 adults) were included in the study. The mean MT was $69.0^{\circ}\left(\mathrm{SD}=14.7^{\circ}\right.$, range $40.1^{\circ}$ to $\left.117.7^{\circ}\right)$ and the mean $\mathrm{TK}$ was $21.8^{\circ}\left(\mathrm{SD}=16.0^{\circ}\right.$, range $-14.0^{\circ}$ to $\left.78.5^{\circ}\right)$. Based on the Lenke classification system, 125 (73.5\%) of the patients were Lenke type 1 and 45 (26.5\%) were Lenke type 2 ; the Lenke sagittal thoracic modifier showed that $43(25.3 \%)$ patients were hypokyphotic $\left(\mathrm{TK}<10^{\circ}\right), 106$ $(62.4 \%)$ were normokyphotic and 21 (12.4\%) were hyperkyphotic $\left(\mathrm{TK}>40^{\circ}\right)$.

\section{Forced expiratory volume in one second $\left(\mathrm{FEV}_{\mathbf{1}}\right)$}

The mean $\mathrm{FEV}_{1}$ was $69.1 \%$ of predicted values with 128 patients $(75.3 \%)$ showing a $\mathrm{FEV}_{1}$ below LLN ( $z$-score below - 1.645); 21 had severe impairment (below $50 \%$ of predicted), 26 had moderate impairment (between 50\% and 60\% of predicted) and 80 had mild impairment (between $60 \%$ and $80 \%$ of predicted). Table 3 shows the correlation coefficients between lung function $z$-scores, Cobb angles, thoracic deformity parameters and lung parameters. $\mathrm{FEV}_{1} z$-scores negatively correlated with both MT and PT $\left(r_{\mathrm{s}}=-0.40\right.$ and -0.24 , respectively, $q<0.01)$ and positively with TK $\left(r_{\mathrm{s}}=0.23, q=0.03\right)$. On PA radiographs, $\mathrm{FEV}_{1}$ correlated positively with $\mathrm{AVBRr}^{-1}\left(r_{\mathrm{s}}=0.46\right)$ and negatively with RVAD $\left(r_{\mathrm{s}}=-0.29\right)$. Lung parameters correlating negatively with $\mathrm{FEV}_{1}$ were $\mathrm{DVL}_{\mathrm{R}}, \mathrm{DVL}_{\mathrm{L}}$ and $\mathrm{LHWr}\left(r_{\mathrm{s}}=-0.36\right.$, -0.30 and -0.28 , respectively). On lateral radiographs, $\mathrm{FEV}_{1}$ was found to correlate negatively with RHDi, SIr and RHi ( $r_{\mathrm{s}}=-0.52,-0.50$ and -0.27 , respectively); and positively with $\mathrm{KLi}$ and $\operatorname{SVDr}\left(r_{\mathrm{s}}=0.26\right.$ and 0.24 , respectively).
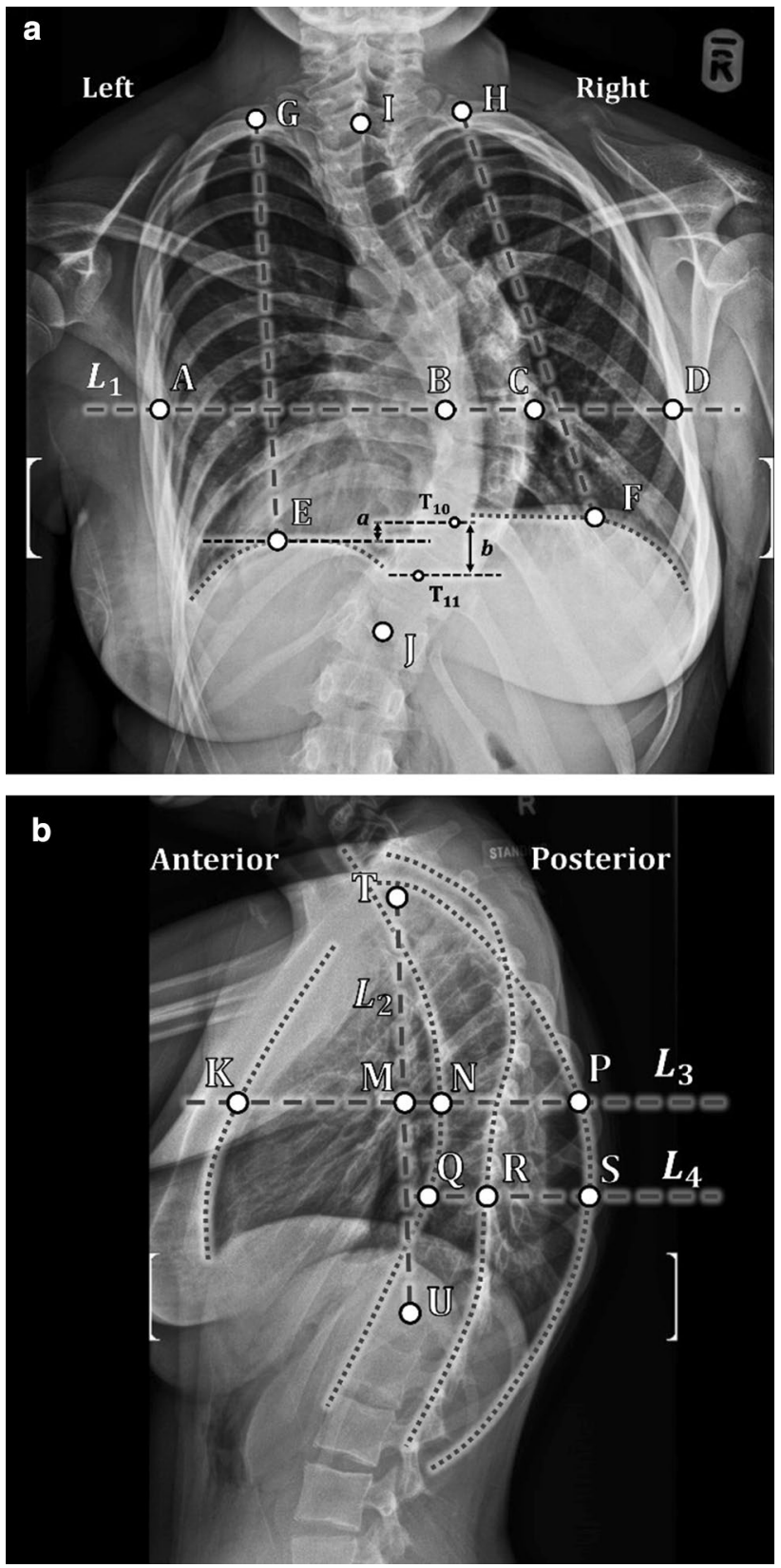

LASSO regression of $\mathrm{FEV}_{1} z$-scores using only Cobb angles yielded a model with an $R^{2}$ of 0.347 with a RMSE of 1.02; MT $(\beta=-0.45, p<0.001)$ and TK $(\beta=0.24$, $p<0.001)$ were found to be major predictors, whilst the effect of PT was unimportant $(\beta=-0.03, p=0.14)$. OLS regression using $\mathrm{MT}(\beta=-0.57, p<0.001)$ and $\mathrm{TK}$ $(\beta=0.35, p<0.001)$ as predictors produced a model with an $R^{2}$ of 0.346 .

LASSO regression using all deformity parameters and Cobb angles produced a model with an $R^{2}$ of 0.594 and RMSE of 0.81. Major predictors included $\operatorname{SIr}(\beta=-0.35$, $p<0.001), \operatorname{AVBRr}^{-1}(\beta=0.21, p<0.001), \operatorname{MT}(\beta=-0.17$, $p<0.001)$, RHDi $(\beta=-0.15, p<0.001)$ and LHWr 
Table 2 Summary of subject characteristics $(n=170)$

\begin{tabular}{|c|c|c|c|}
\hline \multicolumn{4}{|l|}{ Continuous variables, mean (standard deviation) (range) } \\
\hline Age at PFT (years) & 15.1 & $(3.5)$ & (10.0 to 39.8$)$ \\
\hline Standing height $(\mathrm{cm})$ & 161.6 & $(10.2)$ & (133.3 to 190.7$)$ \\
\hline $\operatorname{Arm} \operatorname{span}(\mathrm{cm})$ & 168.1 & $(12.1)$ & (125.0 to 200.0$)$ \\
\hline Weight (kg) & 53.1 & $(13.9)$ & (19.8 to 112.8$)$ \\
\hline $\mathrm{FEV}_{1}(\%$ predicted $)$ & 69.1 & $(15.7)$ & (26.7 to 102.3 ) \\
\hline FVC (\% predicted) & 72.9 & $(15.2)$ & (24.7 to 108.8$)$ \\
\hline $\mathrm{FEV}_{1} / \mathrm{FVC}(\%$ predicted $)$ & 94.2 & $(7.9)$ & (68.6 to 111.5$)$ \\
\hline Proximal thoracic curve $(\mathrm{PT})\left(^{\circ}\right)$ & 33.8 & $(12.6)$ & (12.9 to 87.3$)$ \\
\hline Main thoracic curve $(\mathrm{MT})\left({ }^{\circ}\right)$ & 69.0 & $(14.7)$ & (40.1 to 117.7 ) \\
\hline Thoracic kyphosis $(\mathrm{TK})\left({ }^{\circ}\right)$ & 21.8 & $(16.0)$ & $(-14.0$ to 78.5$)$ \\
\hline Rib vertebral angle difference (RVAD) $\left(^{\circ}\right)$ & 24.5 & $(20.4)$ & $(-30.0$ to 83.3$)$ \\
\hline Inverse apical vertebral body-rib ratio $\left(\mathrm{AVBRr}^{-1}\right)(-)$ & 0.49 & $(0.13)$ & $(0.03$ to 0.74$)$ \\
\hline Thoracic height-width ratio (THWr) (-) & 0.95 & $(0.07)$ & $(0.79$ to 1.26$)$ \\
\hline Lung height-width ratio (LHWr) (-) & 0.86 & $(0.08)$ & (0.62 to 1.09$)$ \\
\hline Space available for lung (SAFL) $(\%)$ & 92.5 & $(7.1)$ & (74.1 to 119.3$)$ \\
\hline Right diaphragmatic vertebral level $\left(\mathrm{DVL}_{\mathrm{R}}\right)(-)$ & 10.90 & $(0.76)$ & (9.10 to 13.63$)$ \\
\hline Left diaphragmatic vertebral level $\left(\mathrm{DVL}_{\mathrm{L}}\right)(-)$ & 10.72 & $(0.71)$ & (8.83 to 12.79$)$ \\
\hline Diaphragmatic vertebral level difference $\left(\mathrm{DVL}_{\text {diff }}\right)(-)$ & -0.18 & $(0.45)$ & $(-1.61$ to 1.11$)$ \\
\hline Kyphosis-lordosis index (KLi) $(\%)$ & 4.48 & $(5.91)$ & $(-12.07$ to 37.40$)$ \\
\hline Spinal intrusion ratio $(\mathrm{SIr})(-)$ & 0.86 & $(0.27)$ & $(0.40$ to 1.89$)$ \\
\hline Rib hump depth index (RHDi) (-) & 0.29 & $(0.05)$ & $(0.20$ to 0.45$)$ \\
\hline Rib hump index (RHi) (-) & 0.53 & $(0.18)$ & (0.11 to 1.16$)$ \\
\hline Sternovertebral depth ratio (SVDr) (-) & 0.35 & $(0.11)$ & $(0.17$ to 0.94$)$ \\
\hline \multicolumn{4}{|l|}{ Categorical variables, $n(\%)$} \\
\hline Sex (females/males) & $121 / 49(71.2 \% / 28.8 \%)$ & & \\
\hline $\mathrm{FEV}_{1}<\mathrm{LLN}^{1}$ & $128(75.3 \%)$ & & \\
\hline $\mathrm{FVC}<\mathrm{LLN}^{1}$ & $117(68.8 \%)$ & & \\
\hline $\mathrm{FEV}_{1} / \mathrm{FVC}<\mathrm{LLN}^{1}$ & $37(21.8 \%)$ & & \\
\hline Lenke type (Type 1/Type 2) & $125 / 45(73.5 \% / 26.5 \%)$ & & \\
\hline Lenke sagittal thoracic modifier $(-/ \mathrm{N} /+)$ & $43 / 106 / 21(25.3 \% / 62.4 \% / 12.4 \%)$ & & \\
\hline
\end{tabular}

${ }^{1}$ Lower limit of normal (LLN) defined as the 5 th percentile ( $z$-score of - 1.645) of the reference population [20]

$(\beta=-0.10, p<0.001)$; the remaining predictors had standardised coefficients of zero. Figure 2 displays the results of the full LASSO regression with plots of standardised regression coefficients $(\beta)$ against the tuning parameter $(\lambda)$ and the observed-predicted plots of the final model. OLS regression using only SIR $(\beta=-0.49, p<0.001)$ and $\mathrm{AVBR}^{-1}$ $(\beta=0.49, p<0.001)$ as predictors produced a model with an $R^{2}$ of 0.537 .

A summary of LASSO and OLS regression models for both $z$-score and per cent-predicted lung function parameters can be found in the online supplementary material.

\section{Forced vital capacity (FVC)}

The mean FVC was $72.9 \%$ of predicted with 117 patients $(68.8 \%)$ showing a FVC below LLN; 13 had severe impairment, 14 had moderate impairment and 86 had mild impairment. FVC $z$-scores negatively correlated with MT $\left(r_{\mathrm{s}}=-0.38, q<0.001\right)$ but did not correlate with PT or TK $(q=0.18$ and 0.25 , respectively). On PA radiographs, FVC correlated positively with $\mathrm{AVBRr}^{-1}\left(r_{\mathrm{s}}=0.42\right)$ and negatively with RVAD $\left(r_{\mathrm{s}}=-0.25\right)$. Lung paramete $r_{\mathrm{s}}$ negatively correlating with $\mathrm{FVC}$ were $\mathrm{DVL}_{\mathrm{R}}, \mathrm{DVL}_{\mathrm{L}}$ and $\mathrm{LHWr}$ $\left(r_{\mathrm{s}}=-0.33,-0.29\right.$ and -0.26 , respectively). On lateral radiographs, FVC correlated negatively with RHDi, SIr and RHi ( $r_{\mathrm{s}}=-0.50,-0.45$ and -0.26 , respectively).

LASSO regression of FVC $z$-scores using only Cobb angles yielded a model with an $R^{2}$ of 0.298 with a RMSE of 1.14; MT $(\beta=-0.42, p<0.001)$ and TK $(\beta=0.14$, $p<0.001)$ were found to be major predictors, whilst the effect of PT was unimportant $(\beta=0, p=0.86)$. OLS regression using MT $(\beta=-0.55, p<0.001)$ and TK $(\beta=0.27$, $p<0.001)$ as predictors produced a model with an $R^{2}$ of 0.306 . 
Table 3 Spearman correlation coefficients $\left(r_{\mathrm{s}}\right)$ between lung function $z$-scores, Cobb angles, thoracic deformity and lung parameters $(n=170)$

\begin{tabular}{|c|c|c|c|c|c|c|}
\hline & $\mathrm{FEV}_{1}$ & FVC & $\mathrm{FEV}_{1} / \mathrm{FVC}$ & PT & MT & TK \\
\hline PT & $-0.24 *$ & -0.18 & -0.14 & - & - & - \\
\hline MT & $-0.40 * * *$ & $-0.38 * * *$ & -0.07 & $0.34 * * *$ & - & - \\
\hline TK & $0.23^{*}$ & 0.17 & $0.25 *$ & -0.01 & $0.26^{* *}$ & - \\
\hline RVAD & $-0.29 * *$ & $-0.25^{*}$ & -0.13 & $0.24 *$ & $0.48 * * *$ & 0.13 \\
\hline $\mathrm{AVBRr}^{-1}$ & $0.46^{* * *}$ & $0.42 * * *$ & 0.13 & $-0.41 * * *$ & $-0.74 * * *$ & -0.16 \\
\hline THWr & 0.12 & 0.11 & 0.04 & $-0.28 * *$ & $-0.54 * * *$ & $-0.25^{*}$ \\
\hline LHWr & $-0.28 * *$ & $-0.26 * *$ & -0.08 & -0.04 & $-0.27 * *$ & $-0.38 * * *$ \\
\hline SAFL & 0.17 & 0.14 & 0.08 & $0.30 * *$ & $-0.47 * * *$ & -0.11 \\
\hline $\mathrm{DVL}_{\mathrm{R}}$ & $-0.36 * * *$ & $-0.33 * * *$ & -0.09 & 0.14 & 0.09 & $-0.25^{*}$ \\
\hline $\mathrm{DVL}_{\mathrm{L}}$ & $-0.30 * *$ & $-0.29 * *$ & -0.07 & 0.16 & -0.11 & $-0.31 * * *$ \\
\hline $\mathrm{DVL}_{\mathrm{diff}}$ & 0.19 & 0.16 & 0.05 & 0.02 & $-0.34 * * *$ & -0.08 \\
\hline $\mathrm{KLi}$ & $0.26^{* *}$ & 0.18 & $0.29 * *$ & -0.10 & 0.20 & $0.80 * * *$ \\
\hline SIr & $-0.50 * * *$ & $-0.45 * * *$ & $-0.24 *$ & 0.16 & -0.03 & $-0.59 * * *$ \\
\hline RHDi & $-0.52 * * *$ & $-0.50 * * *$ & -0.14 & $0.24 *$ & $0.54 * * *$ & -0.07 \\
\hline RHi & $-0.27 * *$ & $-0.26^{* *}$ & -0.02 & 0.07 & $0.53 * * *$ & 0.21 \\
\hline SVDr & $0.24 *$ & 0.18 & 0.18 & -0.03 & $0.35 * * *$ & $0.65 * * *$ \\
\hline
\end{tabular}

Significant correlations with: $* q<0.05 ; * * q<0.01$; and $* * * q<0.001$
LASSO regression using all deformity parameters and Cobb angles produced a model with an $R^{2}$ of 0.543 and RMSE of 0.92. Major predictors included SIr $(\beta=-0.26, p<0.001), \operatorname{AVBRr}^{-1}(\beta=0.22, p<0.001)$, MT $(\beta=-0.17, p=0.001)$, RHDi $(\beta=-0.16, p<0.001)$ and LHWr $(\beta=-0.11, p=0.002)$; the remaining predictors had absolute standardised coefficients of zero or near zero $(|\beta|<0.03)$. OLS regression using only SIR $(\beta=-0.42, p<0.001)$ and $\mathrm{AVBR}^{-1}(\beta=0.50, p<0.001)$ as predictors produced a model with an $R^{2}$ of 0.478 .

\section{FEV $_{1} /$ FVC ratio}

The mean $\mathrm{FEV}_{1} / \mathrm{FVC}$ ratio was $83.0 \%$ or $94.2 \%$ of predicted with $37(21.8 \%)$ patients showing a $\mathrm{FEV}_{1} / \mathrm{FVC}$ ratio below LLN. FEV 1 /FVC $z$-scores correlated positively with both KLi and TK $\left(r_{\mathrm{s}}=0.29\right.$ and 0.25 , respectively) and negatively with $\operatorname{SIr}\left(r_{\mathrm{s}}=-0.24\right)$.

LASSO regression of $\mathrm{FEV}_{1} / \mathrm{FVC} z$-scores using only Cobb angles yielded a model with an $R^{2}$ of 0.061 with a RMSE of 1.0 ; TK ( $\beta=0.10, p=0.002)$ was found to be the only predictor. LASSO regression using all deformity parameters and Cobb angles produced a model with an $R^{2}$ of 0.108 and RMSE of $0.98 . \mathrm{KLi}(\beta=0.13, p=0.006)$ was found to be the only predictor; the remaining predictors had standardised coefficients of zero. OLS regression using only $\mathrm{KLi}(\beta=0.33, p<0.001)$ as a predictor produced a model with an $R^{2}$ of 0.108 .

\section{Cobb angles, thoracic deformity and lung parameters}

MT was found to correlate with both PT $\left(r_{\mathrm{s}}=0.34\right.$, $q<0.001)$ and TK $\left(r_{\mathrm{s}}=0.26, q=0.008\right)$. On PA radiographs, MT correlated negatively with $\mathrm{AVBRr}^{-1}$ and THWr $\left(r_{\mathrm{s}}=-0.74\right.$ and -0.54 , respectively) whilst positively with RVAD $\left(r_{\mathrm{s}}=0.48\right)$. MT correlated negatively with lung parameters SAFL, DVL diff $_{\text {and }} \mathrm{LHWr}$ $\left(r_{\mathrm{s}}=-0.47,-0.34\right.$ and -0.27 , respectively). On lateral radiographs, MT correlated positively with RHDi, RHi and $\operatorname{SVDr}\left(r_{\mathrm{s}}=0.54,0.53\right.$ and 0.35 , respectively).

PT was found to correlate negatively with $\mathrm{AVBRr}^{-1}$ and THWr $\left(r_{\mathrm{s}}=-0.41\right.$ and -0.28 , respectively) whilst positively with SAFL, RVAD and RHDi $\left(r_{\mathrm{s}}=0.30,0.24\right.$ and 0.24 , respectively).

On PA radiographs, TK correlated negatively with THWr $\left(r_{\mathrm{s}}=-0.25\right)$. TK correlated negatively with lung parameters $\mathrm{LHWr}, \mathrm{DVL}_{\mathrm{L}}$ and $\mathrm{DVL}_{\mathrm{R}}\left(r_{\mathrm{s}}=-0.38,-0.31\right.$ and -0.25 , respectively). On lateral radiographs, TK correlated positively with $\mathrm{KLi}$ and $\mathrm{SVDr}\left(r_{\mathrm{s}}=0.80\right.$ and 0.65 , respectively) whilst negatively with $\operatorname{SIr}\left(r_{\mathrm{s}}=-0.59\right)$.

Spearman correlation coefficients between deformity parameters and lung parameters can be found in Tables 4 and 5 . 


\section{Discussion}

Previous attempts to predict lung function from spinal parameters have yielded statistical models which explain less than $20 \%$ of the variance in lung function $\left(R^{2}=0.06\right.$ to 0.19$)$ [1-4]. This study focused on thoracic morphology and pulmonary function in Lenke 1 and 2 curve patterns resulting in a predictive model which was able to predict approximately $60 \%$ of the variance in $\mathrm{FEV}_{1}$ and FVC.

The relationship between radiographic Cobb angles and spirometry results has been extensively studied [1-5, 10]. In the coronal plane, the results support prior findings showing the negative association between MT curve size and per cent-predicted $\mathrm{FEV}_{1}$ or FVC ( $r=-0.3$ to - 0.44) $[1,2,5]$. Although the PT curve has previously been considered a risk factor for loss of lung capacity [4], PT curve size was not an independent predictor for loss of FEV $_{1}$ or FVC. Patients with larger MT curves also exhibited large PT curves and as such had lower lung capacities. TK in isolation has been a variable predictor of $\mathrm{FEV}_{1}$ and FVC ( $r=0.16$ to 0.44$)$ [2-5, 10, 13]. Lateral radiographs underestimate the magnitude of the hypokyphosis; accurate evaluation in the true sagittal plane is likely to produce a stronger relationship with lung function [5]. In this study, TK was significantly correlated with $\mathrm{FEV}_{1}$ but not with FVC on univariate analysis. Only on multivariate regression, using Cobb measurements did TK become a predictive factor for both $\mathrm{FEV}_{1}$ and FVC. TK correlated positively with $\mathrm{FEV}_{1} / \mathrm{FVC}\left(r_{\mathrm{s}}=0.25\right)$.

\section{Parameters measured on PA standing radiograph}

Only a few studies to date have explored the relationship of thoracic deformity parameters with pulmonary function [9-13]. On PA radiographs, $\mathrm{AVBRr}^{-1}$ was moderately associated with $\mathrm{FEV}_{1}$ and FVC. $\mathrm{AVBRr}^{-1}$ correlated strongly with MT, RHi and RVAD which are recognised factors for impaired lung function [10, 11, 13, 22]. Apical vertebra translation has a strong association with rib hump formation [23]. The rib hump is known to reduce chest wall compliance and is a post-operative factor for lung function loss [22, 24]. With increasing lateral translation, more segments are included in the scoliosis negatively affecting lung function [2]. AVBRr ${ }^{-1}$ captures various aspects of thoracic deformity, including the reduction in convex hemithoracic width, lateral vertebral translation at the apex, thoracic rotation and rib deformity making it a better predictor of lung function than MT.

RVAD measures the angular difference of the convex and concave ribs at the apical level. RVAD is a two-dimensional representation of the severity of ribcage deformity involving rotation and apical lordosis [25]. Upadhyay et al. found a weak correlation between RVAD and functional residual capacity [10]. In this study, although it correlated weakly with $\mathrm{FEV}_{1}$ and $\mathrm{FVC}$, RVAD was not an independent predictor of lung function upon multivariate regression.

In patients without scoliosis, the right hemidiaphragm is half a vertebral body higher than the left hemidiaphragm [26]; in this study, the right hemidiaphragm was on average lower. Scoliosis (MT) and narrowing of the convex hemitho$\operatorname{rax}\left(\mathrm{AVBRr}^{-1}\right)$ lowered the right hemidiaphragm. Increased spinal intrusion (SIr), decreased thoracic depth (SVDr) and hypokyphosis (TK) lowered both hemidiaphragms simultaneously. Low diaphragmatic domes were associated with reduced $\mathrm{FEV}_{1}$ and FVC. It seems that for a given lung volume or size, reductions in chest depth are accommodated by a lower diaphragm. Greater disturbance of rib dynamics is present in patients with lordoscoliosis and the low diaphragmatic position may be the result of reduced chest wall compliance [7].

Although lung shortening was caused by scoliosis, it was also associated with kyphosis and larger sternovertebral depth which, paradoxically, resulted in overall higher lung capacity. Tall narrow lungs as seen on PA radiographs are therefore a reflection of the taller thorax produced by hypokyphosis. Karol et al. identified thoracic shortening as a risk factor for impaired lung function in congenital scoliosis [27]. Thoracic height-width ratio (THWr) correlated negatively with scoliosis and kyphosis but was not associated with lung capacity. A relatively wide thorax correlated with greater sternovertebral distance. SAFL was described in the context of thoracic insufficiency in congenital scoliosis with fused ribs [16]. In this study, SAFL captured the shortening of the concave hemithorax in patients with AIS and correlated with scoliosis severity but was not associated to lung function loss.

\section{Parameters measured on lateral standing radiograph}

Dubousset et al. described the spinal penetration index (SPi) which quantifies the relative intrusion of the spine into the thoracic cavity [7]. Ito et al. proposed a simplification to the SPi and described the endothoracic hump ratio $(\mathrm{EHr})$; bronchial obstruction has been reported in patients with an average SPi of $23 \%$ and $\mathrm{EHr}$ of 1.34 [8]. Following the concepts of the SPi and EHr, the SIr is introduced in this study which can be measured on lateral standing radiographs. SIr has a strong relationship with TK, KLi and SVDr and was the only deformity parameter to correlate with $\mathrm{FEV}_{1}$, FVC and $\mathrm{FEV}_{1} / \mathrm{FVC} z$-scores simultaneously. SIr measures the anterior position of the spine relative to the rib hump. SIr captures both the anterior translation produced by the apical 

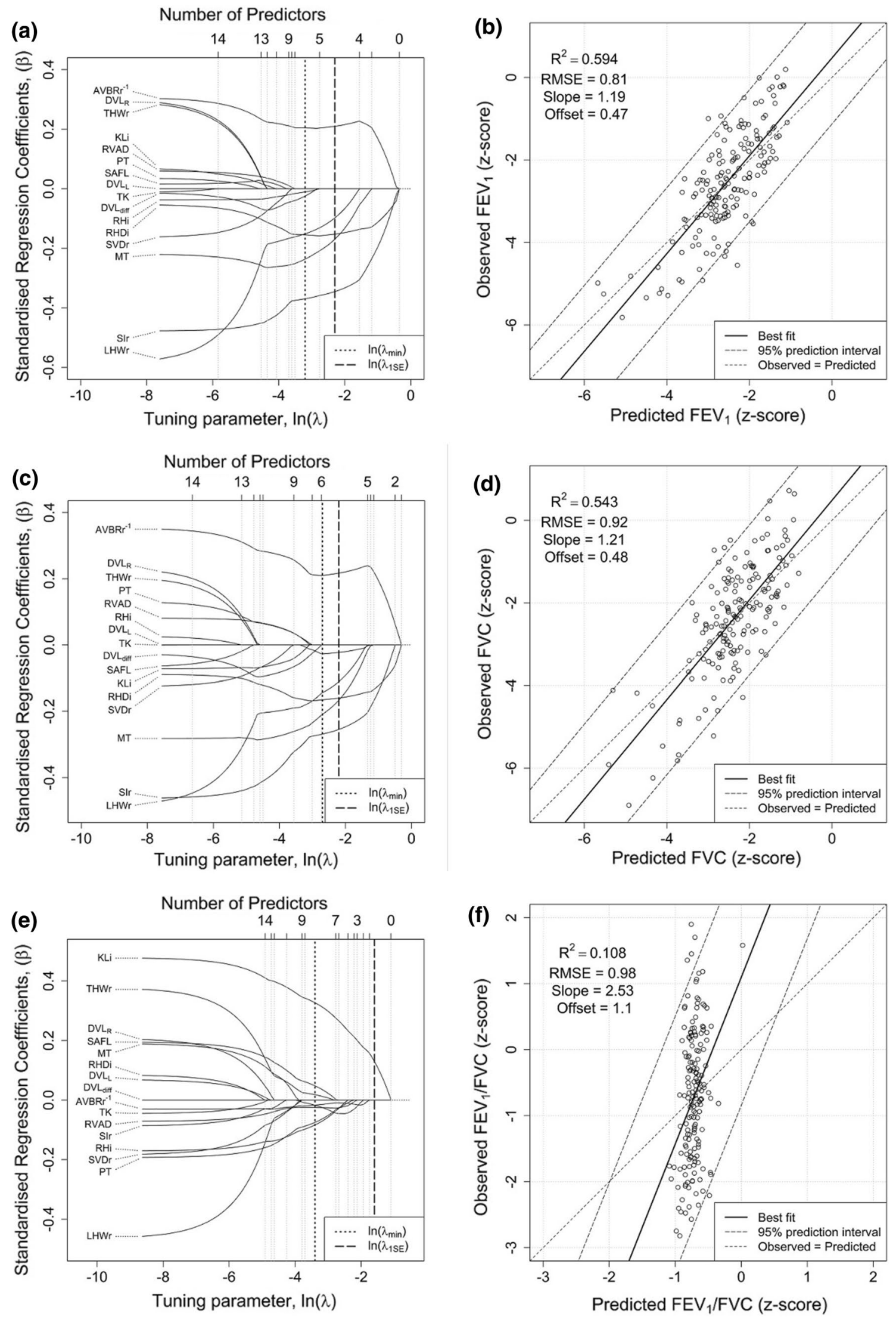
४Fig. 2 Subfigures (a), (c) and (e) plot the standardised regression coefficients $(\beta)$ as a function of the tuning parameter $\lambda$ for the $\mathrm{FEV}_{1}$, FVC and $\mathrm{FEV}_{1} / \mathrm{FVC}$ LASSO regression models, respectively. Subfigures (b), (d) and (f) show the observed-predicted plots for $\mathrm{FEV}_{1}$, $\mathrm{FVC}$ and $\mathrm{FEV}_{1} / \mathrm{FVC} z$-scores, respectively

lordosis [28] as well as the rib hump magnitude produced by axial rotation.

Aaro and Ohlund previously reported the positive association of the sternovertebral distance with $\mathrm{FEV}_{1}$ and FVC measured on axial CT $(r=0.40)$ [11]. Sternovertebral distance measured by biplanar stereoradiography has shown a statistically significant correlation with absolute lung volumes [12]. However, Upadhyay et al. using conventional lateral radiographs was not able to demonstrate significant correlations between the normalised sternovertebral distance and per cent-predicted lung function volumes [10]. In this series, SVDr only correlated weakly with $\mathrm{FEV}_{1} z$-scores.

In a long-term follow-up study of AIS patients after Harrington fusion, the size of the rib hump was a strong predictor of FVC loss [22]. However, as reported in previous studies, RHi is a weak predictor of lung function in preoperative patients with AIS $[12,13]$. Surprisingly, in this study, rib hump depth (RHDi) correlated strongest of all parameters with $\mathrm{FEV}_{1}$ and FVC. RHDi correlated with MT, RHi, $\mathrm{AVBRr}^{-1}$, SIr and negatively with THWr. Torsion of the chest wall and spine causes a lateral and anterior translation of the apical vertebral body. In comparison with RHi, RHDi captures the relative intrusion into the right hemithorax as well as the magnitude of the rib hump.

Thoracic lordosis is a recognised risk factor for airway obstruction in patients with scoliosis [7, 29]. McPhail et al. found the prevalence of obstructive lung disease $\left(\mathrm{FEV}_{1} /\right.$ FVC $<$ LLN) in preoperative patients with AIS to be $39 \%$, but they found no correlation between $\mathrm{TK}$ and $\mathrm{FEV}_{1} / \mathrm{FVC}$ ( $r=-0.13, p=0.09$ ) [3]. In this study, the prevalence was found to be $22 \%$. KLi $\left(r_{\mathrm{s}}=0.29, q=0.002\right)$ correlated stronger with $\mathrm{FEV}_{1} / \mathrm{FVC} z$-scores than $\mathrm{TK}\left(r_{\mathrm{s}}=0.25\right.$, $q=0.012$ ). Whilst the Cobb measurement of kyphosis represents the angulation of the end vertebrae, KLi is a direct measure of anterior displacement of the mid-thoracic spine which can cause right-sided airway narrowing [30]. However, fixed obstruction, atelectasis or lung collapse can render normal $\mathrm{FEV}_{1} / \mathrm{FVC}$ ratios in the presence of airway narrowing in scoliosis [8]. Further diagnostic workup to rule out airway obstruction should be considered for patients with disproportionate lung function loss and hypokyphotic sagittal profiles-even if the $\mathrm{FEV}_{1} / \mathrm{FVC}$ ratio is normal.

\section{Regression analysis}

The multivariate regression analysis using coronal and sagittal Cobb measurements yielded a model which explained $35 \%$ and $30 \%$ of the variance in $\mathrm{FEV}_{1}$ and $\mathrm{FVC}$, respectively.
Table 4 Spearman correlation coefficients $\left(r_{\mathrm{s}}\right)$ between thoracic deformity parameters $(n=170)$
Table 5 Spearman correlation coefficients $\left(r_{\mathrm{s}}\right)$ between lung and thoracic deformity parameters $(n=170)$

\begin{tabular}{|c|c|c|c|c|c|c|c|}
\hline & RVAD & $\mathrm{AVBRr}^{-1}$ & THWr & $\mathrm{KLi}$ & SIr & RHDi & RHi \\
\hline $\mathrm{AVBRr}^{-1}$ & $-0.66^{* * *}$ & - & - & - & - & - & - \\
\hline THWr & -0.10 & $0.30 * *$ & - & - & - & - & - \\
\hline $\mathrm{KLi}$ & 0.05 & -0.06 & -0.18 & - & - & - & - \\
\hline SIr & 0.05 & -0.06 & 0.08 & $-0.66 * * *$ & - & - & - \\
\hline RHDi & $0.29 * *$ & $-0.44 * * *$ & $-0.39 * * *$ & -0.11 & $0.42 * * *$ & - & - \\
\hline RHi & $0.37 * * *$ & $-0.41 * * *$ & $-0.22 *$ & $0.27 * *$ & 0.00 & $0.52 * * *$ & - \\
\hline SVDr & 0.15 & -0.20 & $-0.32 * * *$ & $0.65 * * *$ & $-0.81 * * *$ & 0.11 & $0.32 * * *$ \\
\hline
\end{tabular}

Significant correlations with: $* q<0.05 ; * * q<0.01$; and $* * * q<0.001$

\begin{tabular}{lccccc}
\hline & LHWr & SAFL & $D_{\mathrm{R}}$ & $\mathrm{DVL}_{\mathrm{L}}$ & DVL $_{\text {diff }}$ \\
\hline RVAD & 0.03 & $-0.23^{*}$ & 0.17 & -0.01 & $-0.32^{* * *}$ \\
AVBRr $^{-1}$ & 0.06 & $0.33^{* * *}$ & $-0.26^{* *}$ & -0.06 & $0.36^{* * *}$ \\
THWr & $0.64^{* * *}$ & $0.29^{* *}$ & 0.02 & 0.11 & 0.18 \\
KLi & $-0.25^{*}$ & -0.11 & 0.15 & $-0.22^{*}$ & -0.09 \\
SIr & $0.42^{* * *}$ & 0.07 & $0.43^{* * *}$ & $0.43^{* * *}$ & -0.03 \\
RHDi & 0.00 & $-0.27^{* *}$ & $0.25^{* *}$ & 0.18 & -0.16 \\
RHi & -0.05 & -0.21 & 0.06 & -0.01 & -0.15 \\
SVDr & $-0.48^{* * *}$ & $-0.24^{*}$ & $-0.34^{* * *}$ & $-0.38^{* * *}$ & -0.07 \\
\hline
\end{tabular}

Significant correlations with: $* q<0.05 ; * * q<0.01$; and $* * * q<0.001$ 
In descending order, the regression analysis identified five predictors of $\mathrm{FEV}_{1}$ and FVC $z$-scores: SIr, $\mathrm{AVBRr}^{-1}$, MT, RHDi and LHWr. Incorporating all five predictors, the model explained $59 \%$ and $54 \%$ of the variance in $\mathrm{FEV}_{1}$ and FVC $z$-scores, respectively. A regression model incorporating only SIR and $\mathrm{AVBRr}^{-1}$ as predictors yielded a model explaining $54 \%$ and $48 \%$ of the variance for $\mathrm{FEV}_{1}$ and $\mathrm{FVC}$ $z$-scores. AVBRr ${ }^{-1}$ and SIr capture various aspects of the thoracic deformity, including right hemithoracic width, thoracic rotation, spinal intrusion and rib deformity making them better predictors than Cobb measurements.

\section{Limitations of the study}

This single centre study is drawn from consecutive preoperative patients with a relatively severe deformity and includes 12 adults with AIS. Further studies including patients with different diagnosis, age of onset and wider range of deformity are needed to assess the validity of the proposed parameters and the relevance of these on post-operative respiratory outcomes. The observer variation of these new parameters will need to be determined.

\section{Conclusion}

The current study reports thoracic parameters in AIS patients with Lenke 1 and 2 curves measured on preoperative whole-spine standing PA and lateral radiographs. On PA radiographs, PT was not an independent predictor of lung function. Convex hemithoracic width measured by $\mathrm{AVBRr}^{-1}$ has a stronger association with $\mathrm{FEV}_{1}$ and $\mathrm{FVC}$ than Cobb angle measurements of the main thoracic curve. Low diaphragmatic domes were associated with reduced lung capacity, increased spinal intrusion (SIr), decreased sternovertebral distance (SVDr) and hypokyphosis. On the lateral radiograph, the relative intrusion of the spine into the thorax (SIr) and the depth of the convex rib hump (RHDi) are key predictors of $\mathrm{FEV}_{1}$ and FVC. Multivariate analysis showed that a combination of SIR, $\mathrm{AVBRr}^{-1}$, MT, RHDi and LHWr was able to predict approximately $60 \%$ of the variance in $\mathrm{FEV}_{1}$ and FVC. KLi was found to be the best predictor of $\mathrm{FEV}_{1} / \mathrm{FVC}$.

\footnotetext{
Authors' contributions JF and EG devised the study; EG collated the data; JF performed the measurements and statistical analysis; JF and EG analysed and interpreted the results, drafted the manuscript and approved the final version.
}

Funding This study was funded in part by public funding body Engineering and Physical Sciences Research Council, UK, through the Doctoral Training Grant (EP/M508032/1) and K2M Inc.

\section{Compliance with ethical standards}

Conflict of interest JF has received studentship funding provided by the Engineering and Physical Sciences Research Council (EPSRC), UK, and K2M Inc. EG has no conflict of interest to declare.

Availability of data and material Data generated or analysed during this study are included in this published article and its supplementary information files.

Open Access This article is licensed under a Creative Commons Attribution 4.0 International License, which permits use, sharing, adaptation, distribution and reproduction in any medium or format, as long as you give appropriate credit to the original author(s) and the source, provide a link to the Creative Commons licence, and indicate if changes were made. The images or other third party material in this article are included in the article's Creative Commons licence, unless indicated otherwise in a credit line to the material. If material is not included in the article's Creative Commons licence and your intended use is not permitted by statutory regulation or exceeds the permitted use, you will need to obtain permission directly from the copyright holder. To view a copy of this licence, visit http://creativecommons.org/licenses/by/4.0/.

\section{References}

1. Dreimann M, Hoffmann M, Kossow K et al (2014) Scoliosis and chest cage deformity measures predicting impairments in pulmonary function: a cross-sectional study of 492 patients with scoliosis to improve the early identification of patients at risk. Spine 39:2024-2033. https://doi.org/10.1097/BRS.0000000000000601

2. Newton P, Faro FD, Gollogly S et al (2005) Results of preoperative pulmonary function testing of adolescents with idiopathic scoliosis. J Bone Jt Surg 87:1937-1946

3. Mcphail GL, Ehsan Z, Howells SA et al (2015) Obstructive lung disease in children with idiopathic scoliosis. J Pediatr 166:10181021. https://doi.org/10.1016/j.jpeds.2014.12.070

4. Johnston CE, Stephens Richards B, Sucato DJ et al (2011) Correlation of preoperative deformity magnitude and pulmonary function tests in adolescent idiopathic scoliosis. Spine 36:1096-1102. https://doi.org/10.1097/BRS.0b013e3181f8c931

5. Yaszay B, Bastrom TP, Bartley CE et al (2017) The effects of the three-dimensional deformity of adolescent idiopathic scoliosis on pulmonary function. Eur Spine J 26:1658-1664. https://doi. org/10.1007/s00586-016-4694-y

6. Harris JA, Mayer OH, Shah SA et al (2014) A comprehensive review of thoracic deformity parameters in scoliosis. Eur Spine J 23:2594-2602. https://doi.org/10.1007/s00586-014-3580-8

7. Dubousset J, Wicart P, Pomero V et al (2003) Spinal penetration index: new three-dimensional quantified reference for lordoscoliosis and other spinal deformities. J Orthop Sci 8:41-49. https ://doi.org/10.1007/s007760300007

8. Ito K, Kawakami N, Miyasaka K et al (2012) Scoliosis associated with airflow obstruction due to endothoracic vertebral hump. Spine 37:2094-2098. https://doi.org/10.1097/BRS.0b013 e31825d2ea3

9. Ilharreborde B, Dubousset J, Skalli W, Mazda K (2013) Spinal penetration index assessment in adolescent idiopathic scoliosis using EOS low-dose biplanar stereoradiography. Eur Spine J 22:2438-2444. https://doi.org/10.1007/s00586-013-2892-4

10. Upadhyay SS, Mullaji AB, Luk KD, Leong JC (1995) Relation of spinal and thoracic cage deformities and their flexibilities 
with altered pulmonary functions in adolescent idiopathic scoliosis. Spine 20:2415-2420

11. Aaro S, Ohlund C (1984) Scoliosis and pulmonary function. Spine 9:220-222. https://doi.org/10.1097/00007632-19840 3000-00015

12. Bouloussa H, Pietton R, Vergari C et al (2019) Biplanar stereoradiography predicts pulmonary function tests in adolescent idiopathic scoliosis: a cross-sectional study. Eur Spine J 28:1962-1969. https://doi.org/10.1007/s00586-019-05940-3

13. Takahashi S, Suzuki N, Asazuma T et al (2007) Factors of thoracic cage deformity that affect pulmonary function in adolescent idiopathic thoracic scoliosis. Spine 32:106-112. https:// doi.org/10.1097/01.brs.0000251005.31255.25

14. Mehta MH (1972) The rib-vertebra angle in the early diagnosis between resolving and progressive infantile scoliosis. J Bone Joint Surg Br 54B:230-243. https://doi. org/10.1302/0301-620X.54B2.230

15. Kuklo TR, Potter BK, Lenke LG (2005) Vertebral rotation and thoracic torsion in adolescent idiopathic scoliosis. J Spinal Disord Tech 18:139-147. https://doi.org/10.1097/01.bsd.0000159033.89623.bc

16. Campbell R, Smith M, Mayes T et al (2003) The characteristics of thoracic insufficiency syndrome congenital scoliosis. J Bone Jt Surg 85:399-408

17. Vrtovec T, Pernuš F, Likar B (2009) A review of methods for quantitative evaluation of spinal curvature. Eur Spine J 18:593607. https://doi.org/10.1007/s00586-009-0913-0

18. Miller MR, Hankinson J, Brusasco V et al (2005) Standardisation of spirometry. Eur Respir J 26:319-338. https://doi. org/10.1183/09031936.05.00034805

19. Quanjer PH, Capderou A, Mazicioglu MM et al (2014) All-age relationship between arm span and height in different ethnic groups. Eur Respir J 44:905-912. https://doi.org/10.1183/09031 936.00054014

20. Quanjer PH, Stanojevic S, Cole TJ et al (2012) Multi-ethnic reference values for spirometry for the 3-95-yr age range: the global lung function 2012 equations. Eur Respir J 40:1324-1343. https ://doi.org/10.1183/09031936.00080312

21. Benjamini Y, Yekutieli D (2001) The control of the false discovery rate in multiple testing under dependency. Ann Stat 29:11651188. https://doi.org/10.1214/aos/1013699998

22. Akazawa T, Kuroya S, Iinuma M et al (2018) Pulmonary function and thoracic deformities in adolescent idiopathic scoliosis
27 years or longer after spinal fusion with Harrington instrument. J Orthop Sci 23:45-50. https://doi.org/10.1016/j.jos.2017.08.016

23. Easwar TR, Hong JY, Yang JH et al (2011) Does lateral vertebral translation correspond to Cobb angle and relate in the same way to axial vertebral rotation and rib hump index? A radiographic analysis on idiopathic scoliosis. Eur Spine J 20:1095-1105. https ://doi.org/10.1007/s00586-011-1702-0

24. Yamaguchi C (1984) Pulmonary function and movement of the thoracic cage in mild idiopathic thoracic scoliosis. Nihon Seikeigeka Gakkai Zasshi 58:989-1002. https://doi. org/10.1097/01241398-198509000-00071

25. Brink RC, Schlösser TPC, van Stralen M et al (2018) What is the actual 3D representation of the rib vertebra angle difference (mehta angle)? Spine 43:E92-E97. https://doi.org/10.1097/ BRS.0000000000002225

26. Suwatanapongched T, Gierada DS, Slone RM et al (2003) Variation in diaphragm position and shape in adults with normal pulmonary function. Chest 123:2019-2027. https://doi.org/10.1378/ chest.123.6.2019

27. Karol LA, Johnston C, Mladenov K et al (2008) Pulmonary function following early thoracic fusion in non-neuromuscular scoliosis. J Bone Jt Surg 90:1272-1281. https://doi.org/10.2106/ JBJS.G.00184

28. Sullivan TB, Reighard FG, Osborn EJ et al (2017) Thoracic idiopathic scoliosis severity is highly correlated with 3D measures of thoracic kyphosis. J Bone Jt Surg 99:e54. https://doi.org/10.2106/ JBJS.16.01324

29. Bartlett W, Garrido E, Wallis C et al (2009) Lordoscoliosis and large intrathoracic airway obstruction. Spine 34:59-65. https:// doi.org/10.1097/BRS.0b013e318191f389

30. Farrell J, Garrido E (2018) Effect of idiopathic thoracic scoliosis on the tracheobronchial tree. BMJ Open Respir Res 5:e000264. https://doi.org/10.1136/bmjresp-2017-000264

Publisher's Note Springer Nature remains neutral with regard to jurisdictional claims in published maps and institutional affiliations. 